\title{
Effect of isovolaemic haemodilution on visual outcome in branch retinal vein occlusion
}

\author{
Hean C Chen, Jutta Wiek, Anita Gupta, Alan Luckie, Eva M Kohner
}

\begin{abstract}
Aims-To assess the efficacy of isovolaemic haemodilution therapy (IHT) in the treatment of patients with branch retinal vein occlusion (BRVO).

Methods-Patients presenting with BRVO between 1 July 1991 and 31 August 1993 were eligible for inclusion and randomised into treatment and control groups. Patients randomised to receive IHT were treated for 6 weeks with venesection and volume replacement using hydroxyethylstarch, a plasma expander. The target haematocrit was $35 \%$. Follow up was for 1 year.

Results-The baseline visual acuity of the two groups was similar at 0.74 and 0.75 logMAR units (Snellen 6/36), for the IHT and control groups, respectively. At 6 weeks, visual acuity in the IHT group had improved by $0.20 \log M A R$ units (2 lines on the Bailey-Lovie chart $)(p=0.0001)$. Vision was unchanged in the control group. At 1 year, the IHT group exhibited an improvement of $0.43 \log$ MAR units. By comparison, the improvement in the control group at 1 year was significantly less at $0.17 \mathrm{log}-$ MAR units $(p=0.03)$. The final visual acuity in the IHT and control groups was 0.30 (Snellen 6/12) and 0.60 (Snellen 6/24) logMAR units, respectively.

Conclusions-The results support the theory that IHT has a positive effect on the visual outcome in patients with BRVO.

(Br F Ophthalmol 1998;82:162-167)
\end{abstract}

There is currently no treatment in the acute stages of branch retinal vein occlusion (BRVO) to reduce microvascular damage. The occlusion in BRVO has been demonstrated to be incomplete where blood flow is slow rather than in a state of no flow. ${ }^{1-7}$ Alternative routes of drainage-that is, a collateral circulation, eventually develop but this may not be evident for several months. ${ }^{489}$

BRVO has been found to be associated with hyperviscosity due to higher haematocrit and plasma viscosity. ${ }^{10-12}$ Higher blood viscosity is less important when blood flow rate is rapid but in conditions of low flow, as is likely in a vein predisposed to occlusion, the effect of viscosity becomes increasingly significant as a result of increased red cell aggregation. Low flow rates are therefore more likely to have an exaggerated effect in patients with higher viscosity. Viscosity is mainly dependent upon the haematocrit (the greater the number of red cells, the larger the aggregates) and plasma fibrinogen (required for aggregation to occur).
The enhanced aggregation at slow flow rates further decreases flow leading to a vicious cycle of increased viscosity promoting increased aggregation which further increases viscosity, resulting in a state of "rheological obstruction". ${ }^{12-14}$

Additionally, the occlusion induced hypoxia will increase blood viscosity as acidosis increases red cell aggregability ${ }^{15}$ and reduces red cell deformability ${ }^{16}$; both these red cell anomalies may pre-exist in patients with RVO. ${ }^{17}{ }^{18}$ The leakage of plasma from the damaged blood-retinal barrier will also produce haemoconcentration, increasing the local haematocrit value.

The aim of this investigation was to study the effect of lowering blood viscosity on the visual outcome in patients with BRVO; this was achieved through reducing blood haematocrit (haemodilution), by venesection and volume replacement with a less viscous fluid, in a randomised, controlled fashion. This form of treatment has been applied, with some success, in the treatment of central retinal vein occlusion. ${ }^{19-21} \mathrm{~A}$ previous small, uncontrolled study employing hypervolaemic haemodilution reported a beneficial effect on two patients with BRVO. ${ }^{22}$

\section{Materials and methods}

All patients with BRVO seen between 1 July 1991 and 31 August 1993 in the Retinal Diagnostic Department, Moorfields Eye Hospital and the Hammersmith Hospital, London were considered for inclusion in the study.

Entry criteria: Patients were recruited if they were within 3 months of their first visual symptoms and had reduced visual acuity. Their blood haematocrit had to be $38 \%$ or greater. Their age had to be between 21 to 75 years. Informed written consent was obtained from all patients.

Exclusion criteria: Patients with retinal or disc neovascularisation at presentation needing photocoagulation were excluded. Medical conditions included: renal, respiratory or cardiac failure; myocardial infarction or stroke within the last 6 months; unstable angina and ischaemic heart disease diagnosed on an electrocardiogram.

The study was approved by the ethics committees of both Moorfields and Hammersmith Hospitals. The initial protocol included all forms of BRVO provided there was macular involvement - that is, the presence of macular oedema. This was subsequently amended to exclude patients with macular BRVO (that is, no quadrantic involvement other than the macular branch), as these patients generally 
Table 1 The Snellen visual acuity equivalent of $\log M A R$ units

\begin{tabular}{ll}
\hline $\begin{array}{l}\text { Snellen visual } \\
\text { acuity }\end{array}$ & $\begin{array}{l}\text { LogMAR } \\
\text { units }\end{array}$ \\
\hline $6 / 60$ & +1.0 \\
$6 / 48$ & +0.9 \\
$6 / 38$ & +0.8 \\
$6 / 30$ & +0.7 \\
$6 / 24$ & +0.6 \\
$6 / 20$ & +0.5 \\
$6 / 15$ & +0.4 \\
$6 / 12$ & +0.3 \\
$6 / 10$ & +0.2 \\
$6 / 7.5$ & +0.1 \\
$6 / 6$ & 0.0 \\
\hline
\end{tabular}

have a better visual prognosis (the three patients with macular BRVO already entered into the study at this time were included in the final analysis).

\section{MEDICAL ASSESSMENT}

A full physical examination was performed to assess medical suitability by a physician (EMK) as well as the following investigations: electrocardiogram, chest $x$ ray (if indicated), blood tests (haemoglobin, haematocrit (packed cell volume), platelet count, white cell differential, erythrocyte sedimentation rate, fibrinogen, sodium, potassium, urea, creatinine, blood glucose, glycated haemoglobin, triglyceride, cholesterol, uric acid, total protein, albumin, globulins) and urinalysis.

\section{OPHTHALMIC ASSESSMENT}

Visual acuity, with appropriate correction, was recorded using a modified, high contrast, purpose built, front lit Bailey-Lovie chart. ${ }^{23}$ Visual acuity measurements were principally assessed by one masked investigator (research nurse technician) who was masked to the status of the patient; on a few occasions, a second investigator did the assessment. The smallest line managed by the patient was recorded (one error was allowed). To allow for easy comparison of acuity between visits, the logarithm of the mean angle of resolution ( $\log$ MAR) was used. This scale for measuring acuity is linear, decreasing by 0.1 unit for each lower line on the chart; the larger the $\log$ MAR unit, the worse the vision (Table 1 ). A three line reduction is equivalent to a doubling of the visual angle.

A full ocular examination, including direct and indirect ophthalmoscopy and slit lamp biomicroscopy, was conducted. Seven standard field stereoscopic colour fundus photographs were taken; these were used to assess the size of the area affected and, subsequently, the degree

Table 2 Patients excluded from the study

\begin{tabular}{lr}
\hline Patients presenting with BRVO & 112 \\
Total number excluded & 78 \\
Duration greater than 3 months & 23 \\
Medical reasons (mainly cardiovascular) & 11 \\
Haematocrit less than 38\% & 3 \\
Symptomless & 6 \\
Outside age range of $21-75$ years & 4 \\
Non-major temporal BRVO & 15 \\
Refused participation & 16 \\
Patients entered into study & 34 \\
\hline
\end{tabular}

Table 3 Patient characteristics upon entry into the study(results are presented as mean $(S D))$

\begin{tabular}{llll}
\hline & Control & Haemodilution & p Value \\
\hline Number & 16 & 18 & \\
Age (years) & $62(9)$ & $63(10)$ & 0.9 \\
Haematocrit (\%) & $42.4(3.7)$ & $43.9(3.5)$ & 0.2 \\
Duration of symptoms (weeks) & $6.5(2.8)$ & $5.7(2.8)$ & 0.4 \\
Visual acuity (logMAR) & $0.75(0.31)$ & $0.74(0.24)$ & 0.95 \\
Mean arterial blood pressure (mm Hg) & $114(12)$ & $115(13)$ & 0.8 \\
Intraocular pressure (mm Hg) & $16.8(3.5)$ & $16.1(2.6)$ & 0.5 \\
Male:female ratio & $10: 6$ & $12: 6$ & 0.6 \\
No on warfarin & 0 & 1 & 0.3 \\
No on aspirin & 2 & 1 & 0.2 \\
No on antihypertensive agents & 6 & 10 & 0.1 \\
\hline
\end{tabular}

${ }^{\star}$ Visual acuity is presented as the $\log$ of the mean angle of resolution $(\log M A R)$. The mean arterial blood pressure is calculated from the diastolic pressure added to $1 / 3$ of the difference between the systolic and diastolic pressures.
Table 4 Type of branch retinal vein occlusion

\begin{tabular}{lcc}
\hline & Control & Haemodilution \\
\hline Major temporal & 11 & 14 \\
Macular & 2 & 1 \\
Hemisphere & 3 & 3 \\
\hline
\end{tabular}

of residual macular pathology. Fluorescein angiography was performed (by EMK and HCC, who were masked to the patient's status) to assess areas of capillary non-perfusion, degree of macular oedema, and presence of new vessels. These examinations were performed at baseline, 6 weeks, 12 weeks, 24 weeks, and 1 year from the commencement of treatment.

OUTPATIENT ISOVOLAEMIC HAEMODILUTION

The patients were randomly allocated to treatment and control groups using a lottery system. Fifty consecutively numbered envelopes were drawn up, comprising 25 each of "treatment" and "control"; they were "shuffled" in batches of 10-that is, five of each and then numbered. The period of haemodilution was 6 weeks; for the first 2 weeks, the treated patients received twice weekly venesections and then weekly for the subsequent 4 weeks.

Haemodilution was performed (by HCC) to maintain the haematocrit below 35\%. Before each venesection, a blood count ascertained the current haematocrit, upon which the decision to perform a further venesection was made. At each treatment session, depending on the haematocrit, up to $500 \mathrm{ml}$ of blood was removed and the volume replaced with an equal volume of Hespan (Du Pont Ltd), a 6\% solution of hydroxyethylstarch, which is a commonly used plasma expander.

A value of $35 \%$ was chosen as the target haematocrit because this has been shown, in systemic veins, to be the optimum venous haematocrit for oxygen delivery; a higher figure would increase resistance and a lower value would impair oxygen carrying capacity. ${ }^{24}$

At the 3 month review, if visual acuity was worse than $0.3 \log$ MAR unit (Snellen equivalent 6/12) and macular oedema was evident clinically with leakage seen on fluorescein angiography, modified grid laser treatment was applied. Treatment, using the argon green laser, was applied over the area of retinal thickening within the macular region. Sector photocoagulation was applied if ocular neovascularisation developed or if, at 3 months, the fluorescein angiogram showed an area of capillary non-perfusion greater than 5 disc areas. ${ }^{25}$

STATISTICAL ANALYSIS

The distribution of results was assessed for normality using the Shapiro Francia W' test. If the data exhibited normal distribution, paired and unpaired Student's $t$ test was used for assessing within and between group differences. If the data did not exhibit normal distribution, Wilcoxon matched pairs signed rank sum test was used. Intergroup differences were also examined with the construction of $\chi^{2}$ tables. Regression analysis was employed to assess the relation between the degree of 
Table 5 Changes in visual acuity (results presented as mean (SD) logMAR units)

\begin{tabular}{llllll}
\hline & Baseline & 6 weeks & 3 months & 6 months & 1 year \\
\hline Control & $0.75(0.3)$ & $0.76(0.4)^{\star}$ & $\begin{array}{l}0.65(0.3)^{\star} \\
(\mathrm{n}=15)\end{array}$ & $\begin{array}{l}0.54(0.3) \dagger \\
(\mathrm{n}=12)\end{array}$ & $\begin{array}{l}0.61(0.4)^{\star} \\
(\mathrm{n}=14)\end{array}$ \\
Haemodilution & $0.74(0.2)$ & $\begin{array}{l}0.54(0.2) \ddagger \\
(\mathrm{n}=18)\end{array}$ & $\begin{array}{l}0.47(0.3) \S \\
(\mathrm{n}=17)\end{array}$ & $\begin{array}{l}0.41(0.3) \ddagger \\
(\mathrm{n}=16)\end{array}$ & $\begin{array}{l}0.31(0.3) \ddagger \\
(\mathrm{n}=17)\end{array}$ \\
& $(\mathrm{n}=18)$ & $\mathrm{p}=0.003$ & $\mathrm{p}=0.1$ & $\mathrm{p}=0.2$ & $\mathrm{p}=0.03$ \\
\hline
\end{tabular}

The $\mathrm{p}$ values indicate the difference in the magnitude of change from baseline, between the two groups, of each follow up period. For example, at 6 weeks, the difference from baseline for the control group was $0.01 \log$ MAR unit $(0.76-0.75)$ and for the haemodiluted group, this difference was $-0.2 \operatorname{logMAR}$ unit (0.54-0.74); the magnitude of change was significantly greater in the haemodiluted group $(\mathrm{p}=0.003)$.

The significance of change in visual acuity within each group between each follow up period and baseline is as follows: ${ }^{\star} \mathrm{p}>0.05 ; \mathrm{t}=0.04 ; \neq \mathrm{p}=0.0001 ; \mathrm{p}=0.0003$

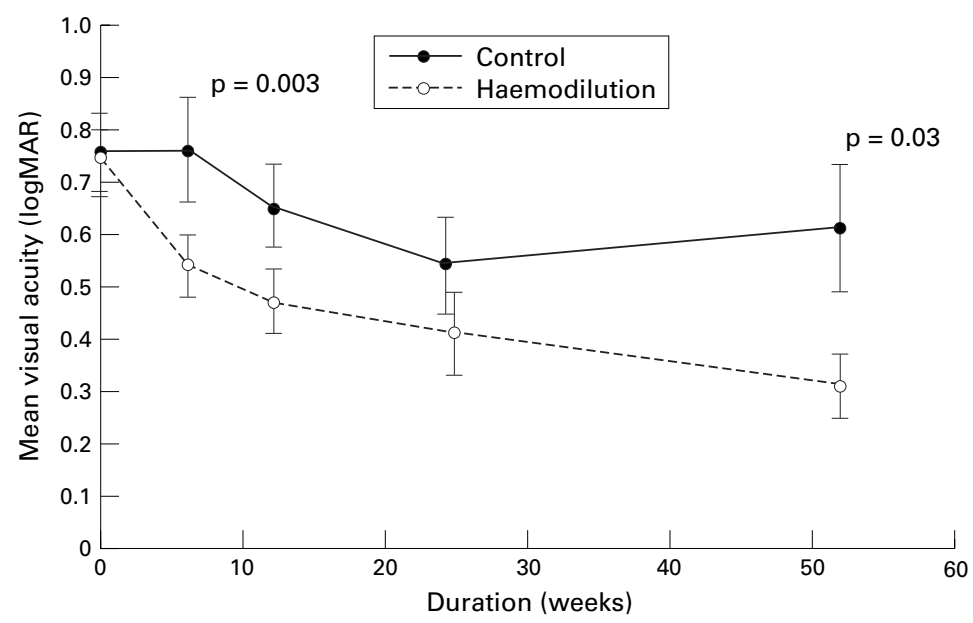

Figure 1 Mean visual acuity. Each point shows the mean visual acuity (vertical bars, mean (SEM)) in both groups of patients from entry into the study to 1 year. The visual acuity is presented in $\log M A R$ units; a decreasing value indicates an improving visual acuity. The $p$ value at which the difference between the two groups reaches statistical significance is shown.
Table 6 Extent of capillary non-perfusion

\begin{tabular}{llc}
\hline No of disc areas & Control & Haemodilution \\
\hline$<5$ & 1 & 0 \\
$5-10$ & 4 & 4 \\
$11-15$ & 2 & 3 \\
$>15$ & 9 & 11 \\
\hline
\end{tabular}

VISUAL ACUITY

The visual acuity data at different times are summarised in Table 5 and Figure 1.

At entry into the study, the mean visual acuity was similar in the haemodiluted and control groups (0.74 and 0.75 , respectively; $p=0.95)$. At the end of the active treatment period-that is, 6 weeks, the haemodiluted group showed a significant mean improvement of 0.2 (from 0.74 to $0.54, p=0.0001$ ), while there was no change in the control group. The degree of improvement achieved by the haemodiluted group was significantly greater than that of the control group (0.2 $v 0.01, \mathrm{p}=0.003)$.

At 1 year, the mean visual acuity was significantly better in the haemodiluted group compared with the control group (0.31 v 0.61, $\mathrm{p}=0.03)$. The haemodiluted group had experienced an increase in visual acuity of 0.43 (from 0.74 to 0.31 ), an improvement in the visual angle of greater than 50\%. Although all haemodiluted patients completed their follow up, the acuity of one patient could not be accurately assessed because of the development of a significant cataract; removing his visual acuity data from the mean baseline value produced little change in its value (from 0.74 to 0.75 ). Only one haemodiluted patient suffered a deterioration in vision; this patient did so because of the subsequent development of a central retinal vein occlusion.

The control patients at 1 year had an insignificant improvement in visual acuity of $0.17(\mathrm{p}=0.1)$. Two of the 16 patients did not complete their follow up; removing their visual acuity values from the mean baseline acuity produced a value of 0.78 (Snellen 6/38) which improved to 0.61 (Snellen 6/24) at 1 year. Of the two patients who failed to attend the 1 year follow up, one had an acuity value that was unchanged from baseline at 6 months and the other had an acuity value which was worse at 6 weeks compared with baseline.

The change in visual acuity in individual patients is shown in Figure 2. At entry, only one haemodiluted patient had vision better than 0.3 (Snellen 6/12), this improved to 6 at 6 weeks and 13 at 1 year. In contrast, this degree of vision was present in three control patients at baseline, two at 6 weeks, and six at 1 year. A significantly larger percentage of haemodiluted patients $(76 \%)$ achieved a final acuity of 0.3 than the control group $(43 \%)(p=0.02)$. This contrasts with the respective baseline values of $12 \%$ and $14 \%$, respectively $(\mathrm{p}=0.4)$.

If the results of the patients with macular branch vein occlusion were removed from analysis, there was no significant change from the pattern of the above results. The visual acuity at baseline, 6 weeks, and 1 year were 0.74 (SD 0.2), $0.52(0.2)$, and 0.31 (0.27), respectively, for the haemodiluted patients of $35 \%$ and did so within 2 weeks of commencement of treatment. 

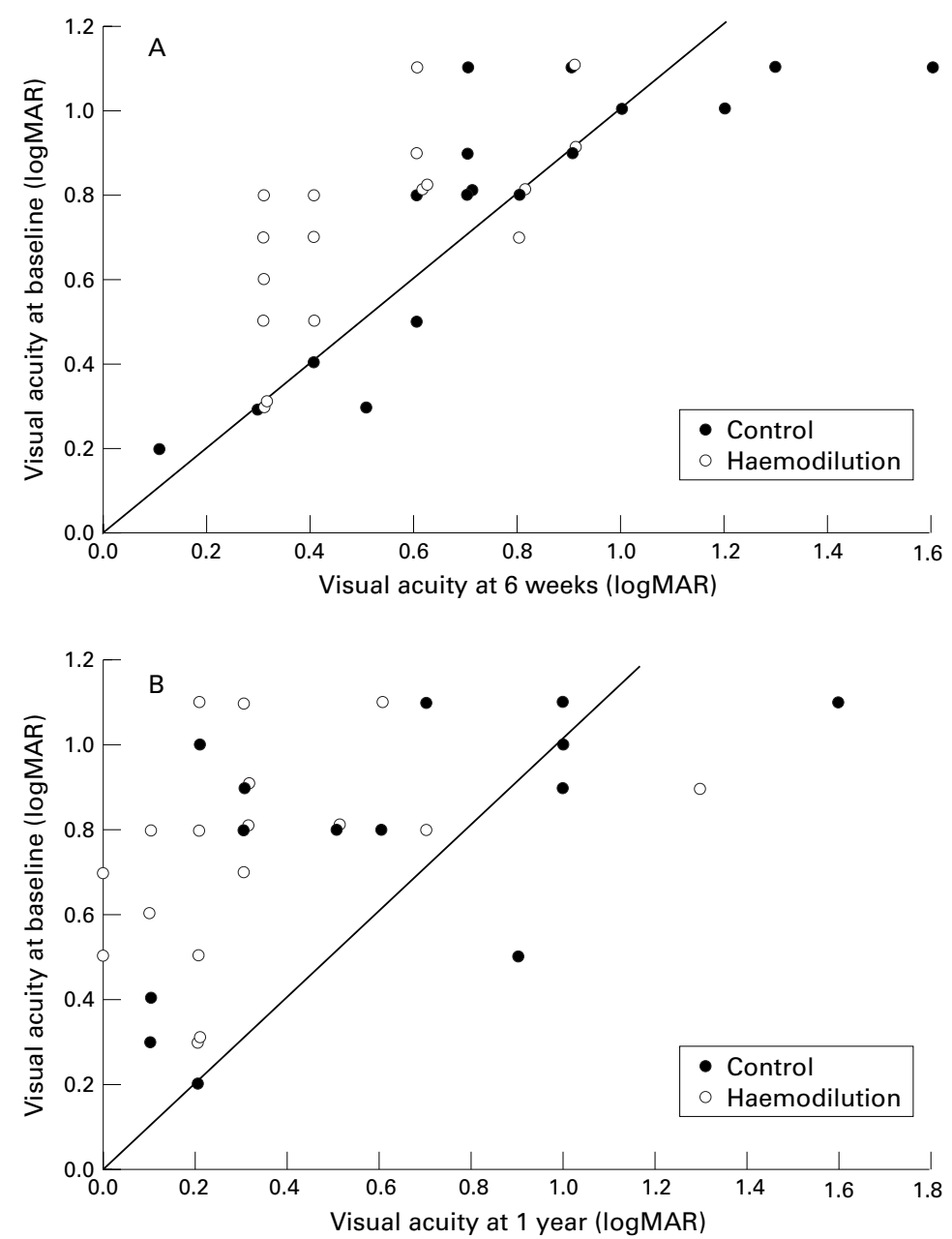

Figure 2 (A) Visual acuity at 6 weeks. This presents the visual acuity at entry into the study and at 6 weeks. Values on the diagonal line are those experiencing no change; those above the line improved and those below deteriorated. (B) Visual acuity at 1 year. This presents the visual acuity at entry into the study and at 1 year. Values on the diagonal line are those experiencing no change; those above the line improved and those below deteriorated.
Table 7 Possible underlying risk factors

列

\begin{tabular}{llc}
\hline & Control & Haemodilution \\
\hline Hypertension & 7 & 9 \\
Atheroma & 2 & 2 \\
Diabetes & 1 & 3 \\
Cholesterol $>6.7 \mathrm{mM} \dagger$ & 3 & 3 \\
Smoking & 8 & 10 \\
IOP $>21 \mathrm{~mm} \mathrm{Hg}$ & 1 & 0 \\
None & 2 & 1
\end{tabular}

$\star$ The presence of systemic atheromatous disease was deduced from the presence of angina, previous myocardial infarction, or cerebral vascular accident and peripheral arterial occlusive disease.

†The upper limit of our laboratory's reference range for plasma cholesterol is $6.7 \mathrm{mM}$.

cally significant $(p=0.2)$. Sector photocoagulation was required by $50 \%$ of both groups of patients, for significant areas of capillary non-perfusion.

MEDICAL ASSOCIATIONS

Medical and ophthalmic conditions known to be associated with retinal vein occlusion are presented in Table 7 . These risk factors were evenly distributed between the two groups.

There was a tendency for those haemodiluted patients with the higher baseline haematocrit to achieve a greater improvement in visual acuity $\left(\mathrm{R}^{2}=0.203, \mathrm{p}=0.0699\right)$; although not significant at the $95 \%$ confidence level, this suggests a "dose related" treatment effect. There was also a tendency for the treated patients with the greatest improvement in acuity to be younger $\left(\mathrm{R}^{2}=0.187, \mathrm{p}=0.09\right)$. A similar association between age and improvement in acuity was not observed in the control group $\left(\mathrm{R}^{2}=0.158, \mathrm{p}=0.2\right)$. No correlation was found between duration of disease before institution of treatment and outcome. No significant complications occurred as a result of the treatment. Two patients felt light headed after their first treatment sessions; both were on systemic $\beta$ blockers for hypertension. A few patients reported feeling a little more tired than normal but none suffered any problems with exertion. No reactions to hydroxyethylstarch were observed.

$(n=17)$; the values at 6 weeks and 1 year were significantly different from baseline $(p=0.0001)$. The equivalent acuity values for the control group $(\mathrm{n}=14)$ were $0.81(0.3), 0.83$ $(0.4)$, and $0.68(0.4)$; the values for 6 weeks and 1 year were not significantly different from baseline ( $p=0.81, p=0.15$ respectively). The change in visual acuity at both time points was significantly different between the two groups, $\mathrm{p}=0.003$ and $\mathrm{p}=0.05$, respectively.

RETINAL APPEARANCE

The variety of BRVO was similar between the two groups (see Table 4). All patients suffered from macular oedema at entry into the study; none developed symptoms because of neovascularisation. Fluorescein angiograms recorded at 3 months or more, when haemorrhages had absorbed to an extent to allow observation of capillary details, were examined for the extent of capillary non-perfusion (Table 6). There was no significant difference between the two groups of patients.

Only $28 \%$ of the haemodiluted patients required macular grid laser treatment for persistent oedema compared with $44 \%$ in the control group; this difference was not statisti-

\section{Discussion}

This study has demonstrated that isovolaemic haemodilution, commenced within 3 months of the onset of symptoms of a BRVO, accelerates the rate of visual recovery and also has a positive effect on the final visual acuity at 1 year. The results of this study reflect those of patients with CRVO treated with IHT - that is, a significantly faster rate of improvement in visual acuity in treated patients from reduced macular pathology. ${ }^{19-21} 26$ Although macular grid photocoagulation treatment was applied in the present study, and may have contributed towards the improvement in visual acuity, the haemodiluted group had shown a significant improvement by 6 weeks which was before the institution of laser treatment. Both groups were similarly treated with laser and, therefore, the effect of laser treatment should be similarly distributed.

The rationale behind the treatment was to increase blood flow through the occluded segment by reducing haematocrit which is trans- 
lated through to both reduced blood viscosity and red cell aggregation. Improved blood flow will lower intracapillary pressure and improve perfusion of the affected region.

The beneficial effect of IHT suggests that the damage sustained by some of the macular capillaries within the first 3 months is potentially reversible if blood flow is improved.

A reduction in intravascular pressure should reduce the rate of leakage and prevent further damage to the compromised barrier. The effect of chronic macular oedema is commonly the development of cystoid features, with decreased photoreceptor numbers and reactive retinal pigment epithelial changes. ${ }^{27}{ }^{28}$ In the present study photographic assessment revealed that of the seven patients with moderate to severe degrees of retinal pigment epithelial atrophy, subretinal fibrosis, or both, in the macular region, five were in the control group.

IHT was found to have no effect on the extent of capillary non-perfusion. It is unclear at what stage capillary non-perfusion occurs; the masking of fluorescence in angiograms by haemorrhage prevented analysis in the early part of the disease process. Experimental work suggests that capillary damage is an early occurrence. ${ }^{8929}$ Any acute intervention is, therefore, likely to be of benefit only if instituted early. Pournaras et al reported capillary non-perfusion even after early recanalisation of the blocked vein. ${ }^{29}$ It may be that the greater density of macular capillaries, allows it a larger "reserve" making it more amenable to treatment, in spite of dropout. ${ }^{30}$ Patients with a broken perifoveolar arcade have experienced an improvement in visual acuity once the oedema subsided. ${ }^{31}$

It has previously been demonstrated that the effect of the treatment lasts for as long as 3 months, in spite of the treatment period being only 6 weeks. ${ }^{19}$ When the effects of treatment have subsided, the initial occlusive pathology may still be present and the rheological obstruction may remanifest itself. This is a possibility, but a collateral circulation is usually established by 3 months ${ }^{4}$ and, therefore, even if IHT only has a temporary effect, this period may be sufficient for a collateral circulation to become established. Once established, a depressurised capillary system will be maintained when the haematocrit returns to pretreatment levels. That visual acuity in the treated patients continued to improve beyond 3 months suggests that this is so.

A target haematocrit of $35 \%$ was selected as it has been demonstrated, albeit in circulatory beds other than the retinal, that this is possibly the optimal haematocrit for oxygen delivery. ${ }^{24}$ Crowell and Smith calculated that the optimum haematocrit increases with the size of the vessel and, therefore, for retinal vessels, the optimum haematocrit should be lower than that for larger systemic vessels. ${ }^{32}$ Mirhashemi et al stated that haemodilution was particularly effective at improving tissue oxygenation in ischaemic tissues with minimal effect on normal tissues, and reported a $36-66 \%$ increase in flow at a haematocrit range of $30-33 \% .^{33}$ It has also been demonstrated that the effect of haemodilution produces a relatively larger fall in haematocrit in larger vessels compared with the microvascular haematocrit ${ }^{34}{ }^{35}$ : this effect optimises the effect of haemodilution in ischaemic conditions as it reduces viscosity at the site of the occlusion (that is, in the larger vessel) while capillary haematocrit is altered to a lesser extent, thus increasing blood flow rate with a relatively unchanged oxygen carriage capacity, which should result in increased oxygen delivery.

Hydroxyethylstarch was chosen because of its capacity to expand the plasma volume by up to $172 \%$ of the volume infused and has a duration of action of approximately 36 hours. ${ }^{36}$ It is non-antigenic and has a low incidence of allergic reactions. ${ }^{37} \mathrm{~A}$ colloidal solution was used in preference to a crystalloid solution as it remains within the circulation for significantly longer periods. In a study comparing the haemodilution effect of hydroxyethylstarch and Ringer's solution, the effect of the latter solution was found to be short lived and insignificant; more importantly, hydroxyethylstarch increased cerebral blood flow, an effect not seen with Ringer's solution. ${ }^{38}$

No major side effects were noted in this study; this was also the experience of Hansen et al. ${ }^{19-21}$ However, reported complications of haemodilution include deep vein thrombosis ${ }^{39}$ and hypotension. ${ }^{40}$

In conclusion, this study has demonstrated that isovolaemic haemodilution has a beneficial outcome on visual acuity in patients with a branch retinal vein occlusion.

The authors would like to thank Grace Vanterpool for coordinating the study.

The study was partly supported by research grants from the Hammersmith Hospital and Moorfields Eye Hospital.

1 Rubinstein K. Arterial insufficiency in retinal venous occlusion (A short symposium). Trans Ophthalmol Soc UK 1964;84:564-81.

Seitz R. The retinal vessels. Tr: Blodi FC. St Louis: CV Mosby, 1964.

3 Oosterhuis JA. Fluorescein fundus photography in retinal vein occlusion. In: Henkes HE, ed. Perspective in ophthalmolvein occlusion. In: Henkes HE, ed. Perspective in opht

ogy. Amsterdam: Excerpta Medica, 1969:29-47.
4 Wise GN, Dollery CT, Henkind P. The retinal circulation. Wise GN, Dollery CT, Henkind P.

5 Clemett RS. Retinal branch vein occlusion. Changes at the site of obstruction. Br f Ophthalmol 1974;58:548-54.

6 Kohner EM, Shilling JS. Retinal vein occlusion. In: Clifford-Rose F, ed. Medical ophthalmology. London: Chapman and Hall, 1976; chapter 28:391-429.

7 Orth DH, Patz A. Retinal branch vein occlusion. Surv Ophthalmol 1978;22:357-76.

8 Kohner EM, Dollery CT, Shakib M, et al. Experimental branch retinal branch vein occlusion. Am $\mathcal{f}$ Ophthalmol 1970;69:778-825.

9 Hockley DJ, Tripathi RC, Ashton N. Experimental retinal branch vein occlusion in the monkey. Trans Ophthalmol Soc UK 1976;96:202-9.

10 McGrath MA, Wechsler F, Hunyor ABL, Penny R. Systemic factors contributing to retinal vein occlusion. Arch Intern Med 1978;138:216-20.

11 Ring R, Pearson TC, Sanders MD, Wetherley-Mein G. Viscosity and retinal vein thrombosis. $\mathrm{Br} f$ Ophthalmol 1976;60:397-410.

12 Trope GE, Lowe GDO, McArdle BM, et al. Abnormal blood viscosity and haemostasis in long-standing retinal vein occlusion. Br f Ophthalmol 1983;67:137-42.

$13 \mathrm{Schmid-Schönbein} \mathrm{H.} \mathrm{Critical} \mathrm{closing} \mathrm{pressure} \mathrm{or} \mathrm{yield}$ shear stress as the cause of disturbed peripheral circulation. Acta Chir Scand 1976;suppl 465:10-9.

14 Ashton N. Pathophysiology of retinal cotton wool spots. $\mathrm{Br}$ Med Bull 1970;26:143-50.

15 Murphy JR. The influence of $\mathrm{pH}$ and temperature on some physical properties of normal erythrocytes and erythrocytes from patients with hereditary spherocytosis. Lab Clin Med 1967;69:758-75.

16 Thomas DJ. Whole blood viscosity and cerebral blood flow. Stroke 1982;13:285-7. 
17 Chabanel A, Glacet-Bernard A, Lelong F, Taccoen A, Coscas $\mathrm{G}$. Increased red blood cell aggregation in retina vein occlusion Br f Haematol 1990;75:127-31.

18 Peduzzi M, Debbia A, Guerrieri G, Bolzani R. Abnormal blood rheology in retinal vein occlusion. A preliminary report. Graefes Arch Clin Exp Ophthalmol 1986;224:83-5.

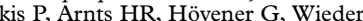
holt $M$. A randomised prospective study on treatment of central retinal vein occlusion by isovolaemic haemodilution and photocoagulation. Br $\mathcal{F}$ Ophthalmol 1985;69:108-16.

20 Hansen LL, Wiek J, Wiederholt M. A randomised prospective study of treatment of non-ischaemic central retinal vein
occlusion by isovolaemic haemodilution. Br $\mathcal{F}$ Ophthalmol 1989;73:895-9.

21 Hansen LL, Wiek J, Müller-Stolzenburg N, Wiederholt M. Effect and compatibility of isovolaemic haemodilution in the treatment of ischaemic and non-ischaemic central retinal vein occlusion. Ophthalmologica 1989;199:90-9.

22 Radnot M, Follmann P. Rheomacrodex (dextran) in the treatment of the occlusion of the central retinal vein. Ann treatment of the occlusion

23 Ferris FL III, Kassoff A, Bresnick GH, Bailey I. New visual acuity charts for clinical research. Am f Ophthalmol

24 Self F, McIntire LV, Zanger B. Rheological evaluation of haemoglobinopathies. $\mathcal{F}$ Lab Clin Med 1977;89:488-97.

25 Branch Vein Occlusion Study Group. Argon laser scatte photocoagulation for prevention of neovascularization and vitreous hemorrhage in branch vein occlusion. A randomized clinical trial. Arch Ophthalmol 1986;104:34-41

26 Wiederholt, M, Leonhardt H, Schmid-Schönbein H, Hager H. Die Behandlung von Zentralvenenverschlüssen und Zentralarterienverschlüssen mit isovolämischer Hämodilution. Klin Monatsbl Augenheilkd 1980;173:392-401.

27 Jampol LM. Macular edema. In: Ryan SJ, ed. Retina. St Louis: CV Mosby, 1989; chapter 58:81-8.

28 Tso MOM. Pathology of cystoid macular edema. Ophthalmology 1982;89:902-15.
29 Pournaras CJ, Tsacopoulos M, Strommer K, Gilodi N, Leuenberger PM. Experimental retinal branch vein occlusion in miniature pigs induces local tissue hypoxia and vasoproliferative microangiopathy. Ophthalmology 1990;97:

30 Alm A. Ocular circulation. In: Hart WM Jr, ed. Adler's physiology of the eye. St Louis: Mosby Year Book, 1992; chapter 6:198-227.

31 Finkelstein D. Ischemic macular edema. Recognition and favorable natural history in branch vein occlusion. Arch Ophthalmol 1992;110:1427-34

32 Crowell JW, Smith EE. Determinant of the optimal hematocrit. F Appl Physiol 1967;22:501-4.

33 Mirhashemi S, Ertefai S, Messmer K, Intaglietta M. Model analysis of the enhancement of tissue oxygenation by hemodilution due to increased microvascular flow velocity. Microvasc Res 1987;34:290-301.

34 Jung F, Koscielny J, Mrowietz C, et al. Effect of hemodilution on systemic and capillary hematocrit. Infusionstherapie 1990;17:268-75.

35 Lipowsky HH, Firrell JC. Microvascular hemodynamics during systemic hemodilution and hemoconcentration. $\mathrm{Am}$ f Physiol 1986;250:H908-22.

36 Hulse JD, Yacobi A. Hetastarch: an overview of the colloid and its metabolism. Drug Intell Clin Pharm 1983;17:33441

37 Waters LM, Christensen MA, Sato RM. Hetastarch: an alternative colloid in burn shock management. F Burn Care Rehab 1989;1:11-6.

38 Scharf J, von Kummer R, Back T, et al. Haemodilution with dextran 40 and hydroxyethyl starch and its effect on cerebral microcirculation. F Neurol 1989;236:164-7.

39 Janvrin SB, Davies G, Greenhalgh RM. Postoperative deep vein thrombosis, an association with haemodilution. $\mathrm{Br} F$ Surg 1980;67:690-3.

40 Kiraly JF III, Feldmann JE, Wheby MS. Hazards of phlebotomy in polycythemic patients with cardiovascular disease. $7 A M A$ 1976;236:2080-1. 